\title{
Damping Property of a Cement-Based Material Containing Carbon Nanotube
}

\author{
Wei-Wen Li, ${ }^{1}$ Wei-Ming Ji, ${ }^{1}$ Yi Liu, ${ }^{1}$ Feng Xing, ${ }^{1}$ and Yu-Kai Liu ${ }^{2}$ \\ ${ }^{1}$ Guangdong Key Provincial Durability Center for Marine Structure, Shenzhen Durability Center for Civil Engineering, \\ Department of Civil Engineering, Shenzhen University, Shenzhen 518060, China \\ ${ }^{2}$ Shenzhen Graduate School of Harbin Institute of Technology, Shenzhen 518055, China \\ Correspondence should be addressed to Yi Liu; 1208234213@qq.com
}

Received 29 September 2015; Revised 4 December 2015; Accepted 6 December 2015

Academic Editor: Stefano Bellucci

Copyright (C) 2015 Wei-Wen Li et al. This is an open access article distributed under the Creative Commons Attribution License, which permits unrestricted use, distribution, and reproduction in any medium, provided the original work is properly cited.

\begin{abstract}
This study aimed to explore the damping property of a cement-based material with carbon nanotube (CNT). In the study, the cement composites with different contents of CNT ( $0 \mathrm{wt} \%, 0.033 \mathrm{wt} \%, 0.066 \mathrm{wt} \%$, and $0.1 \mathrm{wt} \%)$ were investigated. Logarithmic Decrement method and Dynamic Mechanical Analysis (DMA) method were utilized to study the damping property of CNT/cement composite. The influences of CNT on pore size distribution and microstructure of composite were analyzed by Mercury Intrusion Porosimetry (MIP) and Scanning Electron Microscopy (SEM), respectively. The experimental results showed that CNT/cement composite presented higher flexural strength index than that of a pure cement paste. Additional CNT could improve the vibrationreduction capacity of cement paste. Furthermore, the experiments proved that CNT could bridge adjacent hydration products and support load transfer within cement matrix, which contributed to the energy dissipation during the loading process.
\end{abstract}

\section{Introduction}

Carbon nanotube $(\mathrm{CNT})$ is a prevalent and promising carbon material due to its outstanding properties, as Young's modulus and tensile strength of an individual CNT fiber could reach $1 \mathrm{TPa}$ and $100 \mathrm{GPa}$, respectively, and with a fracture strain of up to $15 \%$ and specific surface area of up to $1000 \mathrm{~m}^{2} / \mathrm{g}$ [1-3]. In addition, CNT is also an excellent conductive material with a conductivity of 1000 2000 S/cm and a current density of up to $106 \mathrm{~A} / \mathrm{cm}^{2}$ [1]. Due to these properties, CNT has been a concern for numerous researchers.

Reinforced concrete structures usually suffer severe situations such as typhoons and earthquake attack, which could cause damage or fatigue accumulations to structures and considerable retrofitting cost to society. Concrete is now the most widely used structural material, but it is confronted with potentially serious damage or fatigue accumulations in severe environments due to unsatisfactory damping property. For example, concrete used to suffer dynamic loading which can be due to live loads, wind, and earthquakes. Requirements for better damping property of concrete are of great significance for the safety and comfort of people. To date, vibration control has been introduced to structures in order to prolong the life of structures and reduce economical cost. Vibration control is a set of technical means that aims to alleviate the dynamic vibration responses and impacts in civil infrastructures. It can be simply divided into three categories: substructure vibration isolating, passive energy dissipation, and active, semiactive, and smart control [4]. Among these methods, a more preferable way to attain higher vibration capacity is to tailor the structural material itself so that it maintains its high strength while providing ideal damping property. Damping is the dissipation of energy in a material under cyclic load. It will be more convenient to improve the damping property by adding mixture into cement matrix than equipping structures with damping devices. So far, it is a common method to add admixtures, including polymers, steel, and carbon fiber, to cement matrix to improve its damping property [5-8].

Based on existing knowledge, CNT can be used as a reinforcing component in cement matrix due to its bonding, bridging, and mesh filling effects [9-11], which can inhibit propagation of microcracks and may contribute to higher 


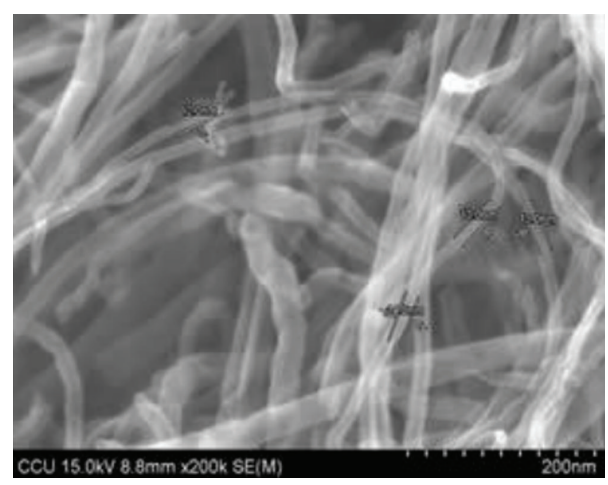

Figure 1: SEM image of MWCNT.

damping property. Lots of efforts have been made to apply CNT to polymer composite for enhancing vibrationreduction capacity. For example, Dai and Liao [12] investigated the damping property of epoxy resin containing $\mathrm{CNT}$ and results showed that CNT addition can provide the composite with better damping property without undergoing large shear strain. Tehrani et al. [13] studied the performances of the hybrid CNT-carbon fiber reinforced epoxy composite and found $56 \%$ improvement on the loss tangent for the hybrid composite with respect to reference sample. To date, studies have investigated polymer composite containing CNT for its promising capacity of enhancing damping property. However, in the aspect of improving damping ability of cement matrix, few researches have been conducted. Besides, influences of the CNT on damping ability of cement composite and its working mechanism have not been introduced yet.

This paper focuses on damping behavior of a cementbased material with CNT. During the study, different concentrations ( $0 \mathrm{wt} \%, 0.033 \mathrm{wt} \%, 0.066 \mathrm{wt} \%$, and $0.1 \mathrm{wt} \%$ ) of MWCNT were mixed into cement paste and the flexural strengths of specimens cured in standard condition for 28 days were tested. Logarithmic Decrement and Dynamic Mechanical Analysis (DMA) were utilized to study the damping property of the $\mathrm{CNT} /$ cement composite. Furthermore, Scanning Electron Microscopy (SEM) was used to observe the morphology, while the porosity of the composite was measured with a Mercury Intrusion Porosimetry (MIP) instrument.

\section{Experimental Programs}

2.1. Materials. The cement used in this study was Type I 42.5R Portland cement manufactured by Guangzhou Xinhe Co., Ltd. The CNT was purified multiwalled CNT (MWCNT) offered by Chengdu Institute of Organic Chemistry Research Institute. Its physical properties and morphology are shown in Table 1 and Figure 1, respectively. The surfactant employed for MWCNT dispersion in water is a polyvinylpyrrolidone (PVP) supplied by the Aladdin Reagents (Shanghai) Co., Ltd. The water used in the experiment was distilled water.

2.2. Manufacture and Curing of Specimens. Prior to preparing the CNT/cement composite, the aqueous dispersion of
TABLE 1: Properties of the MWCNT used in this study.

\begin{tabular}{lccccc}
\hline Type & Diameter & Length & Purity & $\begin{array}{c}\text { Specific } \\
\text { surface } \\
\text { area }\end{array}$ & $\begin{array}{c}\text { Making } \\
\text { method }\end{array}$ \\
\hline MWCNT $10 \sim 20 \mathrm{~nm}$ & $10 \sim 30 \mu \mathrm{m}$ & $>95 \%$ & $>180 \mathrm{~m}^{2} / \mathrm{g}$ & CVD \\
\hline
\end{tabular}

TABLE 2: Mix proportions (g).

\begin{tabular}{lcccc}
\hline Specimen & Cement & Water & MWCNT & PVP \\
\hline C0 & 100 & 45 & 0 & 0 \\
C1 & 100 & 45 & 0.033 & 0.132 \\
C2 & 100 & 45 & 0.066 & 0.264 \\
C3 & 100 & 45 & 0.100 & 0.400 \\
\hline
\end{tabular}

MWCNT was prepared. Required amount of surfactant-PVP was added into water and mixed with a magnetic stirrer for $15 \mathrm{~min}$, followed by addition of MWCNT and further mixing for $10 \mathrm{~min}$. The aqueous suspension of MWCNT was then sonicated with an Ultrasonic Cell Disrupter (JY92-IIN Ultrasonic cell disrupter, Ningbo Scientz Biotechnology Co., Ltd.) for $15 \mathrm{~min}$. The sonicator was set in circulation of $3 \mathrm{~s}$ working and $3 \mathrm{~s}$ intervals in order to avoid suspension overheat.

Mix proportions of specimens are shown in Table 2. In the experiment, samples were casted and cured according to the following procedures:

(1) Required amount of cement was added into the aqueous dispersion followed by mixing with a cement mixer for $5 \mathrm{~min}$ to obtain fresh CNT/cement pastes.

(2) The fresh cement pastes were casted as the following three different dimensions: $280 \times 25 \times 25 \mathrm{~mm}, 100 \times$ $12 \times 5 \mathrm{~mm}$, and $160 \times 40 \times 40 \mathrm{~mm}$. The former two dimensions were for the damping property test; the latter one was for flexural strength test and morphology observation.

(3) The specimens were demolded after 24 hours and cured under $20^{\circ} \mathrm{C}$ and relative humidity $(\mathrm{RH})$ of $95 \%$ until testing.

2.3. Mechanical Properties Study. To study the influence of CNT on the flexural strength of cement paste, three-point bending test was conducted to measure the flexural strength of the CNT/cement composite. The specimens were tested in three-point bending till failure according to ASTM C348. The flexural strength, $F$, was calculated with

$$
F=\frac{3 f L}{2 b h^{2}},
$$

where $f$ is the loading at failure $(\mathrm{N}), L$ is the distance between two supports and is $100 \mathrm{~mm}$ in this work, $b$ is the width of the specimen $(\mathrm{mm})$, and $h$ is the height of the specimen $(\mathrm{mm})$.

2.4. Damping Property Test. In this study, the damping ratio and loss factor were investigated to characterize the damping property of $\mathrm{CNT} /$ cement composite. The damping ratio serves as an arithmetic mean to express the level of damping 


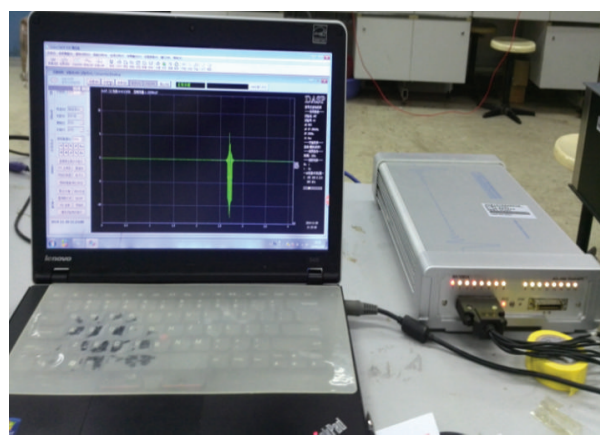

(a) Data acquisition instrument

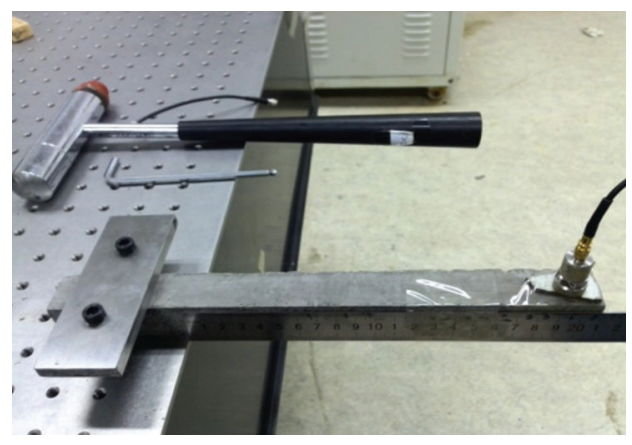

(b) Capacitor piezoelectric accelerometer

FIGURE 2: Vibration instruments.

in a system. The loss factor is a useful and important assessment of materials' viscoelasticity and is also demonstrated as the ability of a material in energy dissipation.

It is a common method to measure the damping ratio of a material by Logarithmic Decrement test $[14,15]$. As shown in Figure 2, time histories of free oscillation of test samples were collected with a capacitor piezoelectric accelerometer (Model: INV3060A) at the mid span of the specimen. A data acquisition instrument (Model: INV9822A) was attached below the specimen and excited by a small hammer with a hard rubber head. The exciting signal is a lightweight and fast hammer impulse with the hammer head being perpendicular to the specimen span and the floor. During the experiment, the sampling frequency was set as $250 \mathrm{~Hz}$. This study investigates the first mode response of the $\mathrm{CNT} /$ cement composite. Figure 3 demonstrates the typical time histories of acceleration attenuation, and the damping ratio, $\xi$, of the free damping signals can be obtained from

$$
\xi=\frac{1}{2 i \pi} \ln \frac{a_{n}}{a_{n+i}},
$$

where $a_{n}$ is the displacement amplitude of the $n$th peak, which can be achieved by calculation from acceleration and frequency, and $a_{n+i}$ is the amplitude of the peak $i$ cycles after the $n$th peak.

The loss factor of a material could be measured by the DMA machine shown in Figure 4 [16]. The $100 \times 12 \times 5 \mathrm{~mm}$ specimens were subjected to a periodic deformation of $7 \mu \mathrm{m}$ with varied frequencies on the 3 -point bending clamp. The temperature was consistent at $25^{\circ} \mathrm{C}$ while the test starts.

2.5. Morphology and Pore Characteristics Study. The morphology observation should be carried out on the crushed sample immediately after the flexural strength tests. Furthermore, for analyzing the pore characteristic, CNT/cement composites cured for 28 days were analyzed with the MIP method.

\section{Results and Analysis}

3.1. Flexural Strength. The average flexural strengths of cement pastes with MWCNT at amounts of $0 \%, 0.033 \%$, $0.066 \%$, and $0.1 \%$ (by weight of cement) at the age of 28 days

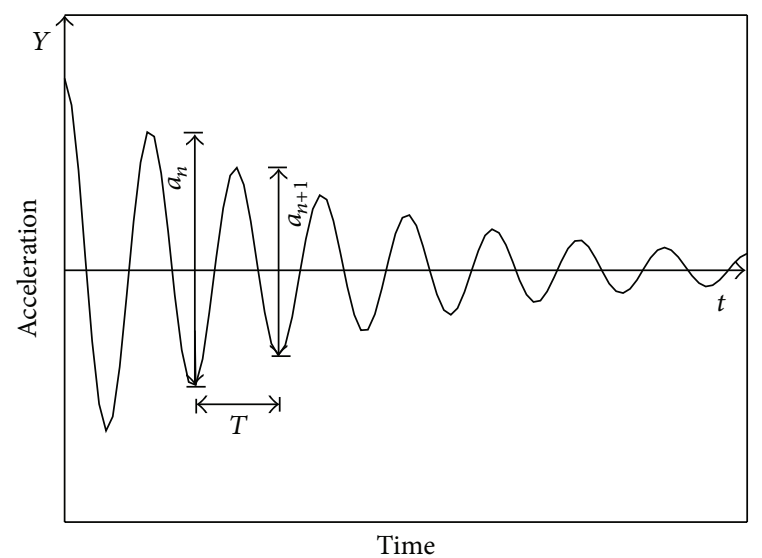

FIgURE 3: The typical curve of acceleration time histories.

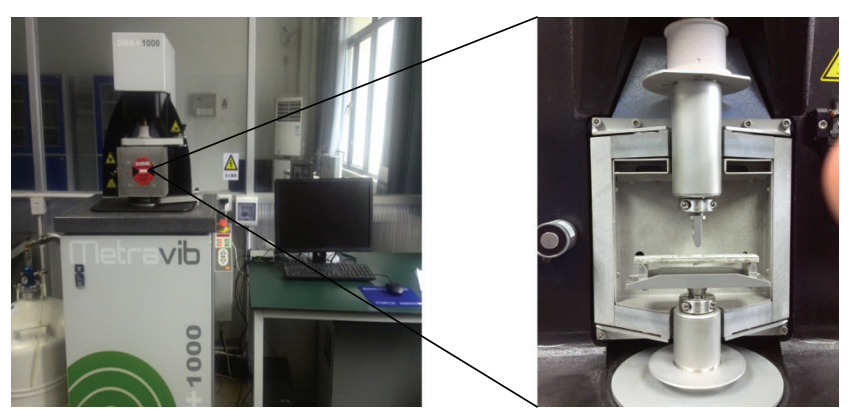

FIGURE 4: DMA instrument.

are presented in Figure 5. As seen from the results, specimens reinforced with MWCNT obtain higher flexural strength with respect to pure cement paste. The highest flexural strength of the specimen was observed in C3 specimen with addition of $0.1 \mathrm{wt} \%$ MWCNT. At the 28th day, it had a $13.2 \%$ higher strength with respect to control specimen $\mathrm{C} 0$. It has been pointed out that the reinforcing effect of the MWCNT in cement matrix primarily depends on its dispersion, which leads to the reduction of the fiber spacing in the nanocomposite $[17,18]$. It was observed that the flexural strength of cement composite increased with increasing content of MWCNT, which also indicated that MWCNT at a higher concentration 


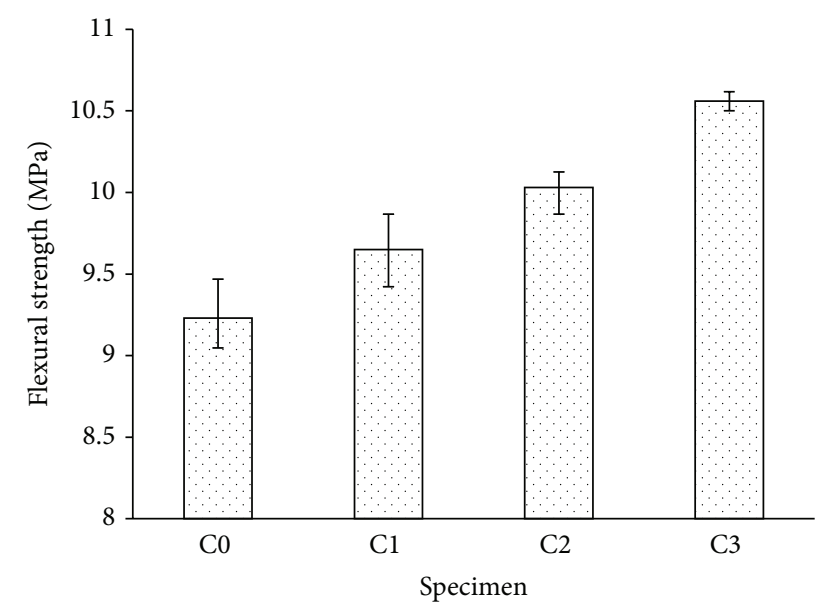

FIGURE 5: Flexural strength of specimens at the age of 28 days.

can be effectively dispersed into cement matrix by means of surfactant in combination with sonication. In this study, the MWCNT is short fiber with length about $10 \sim 30 \mu \mathrm{m}$, and a higher concentration of MWCNT is therefore needed to reduce the fiber free area and arrest the microcracks [18].

The improvement of MWCNT on the flexural strength of cement paste could be attributed to the following reasons. The individual MWCNT interconnected hydration products and played significant roles of bonding and bridging effect for the matrix, which was observed in SEM micrographs in this study. This enhancement can provide higher stress when crack goes straight toward MWCNT reinforced zone area and inhibit development of cracks by dissipating the energy through fiber friction. Furthermore, the network formation of MWCNT that exists between cement hydration products would interlock the $\mathrm{C}-\mathrm{S}-\mathrm{H}$ phases and increase the resistance when crack goes straight forward to this reinforced area [19].

\subsection{Damping Property Testing Results}

3.2.1. Logarithmic Decrement Testing. Figure 6 depicts the free vibration responses of the $\mathrm{CNT} /$ cement composite during the test. Table 3 shows the testing results of damping ratio of the $\mathrm{CNT} /$ cement composite with various contents of MWCNT. It is clearly seen from Table 2 that addition of MWCNT has a great benefit on increasing the damping ratio of cement paste. With increasing the content of MWNCT, the improvement on damping ratio is more obvious. The highest damping ratio of the $\mathrm{CNT} /$ cement composite was observed in C3 specimen with $0.1 \mathrm{wt} \% \mathrm{MWCNT}$. At the 28 th day, it had an $18.3 \%$ higher improvement with respect to pure cement paste.

3.2.2. DMA Testing Results. Figure 7 shows the results of loss factors of CNT/cement composite with various concentrations of MWCNT. As seen from the results, the loss factors of the CNT/cement composite are above that of pure cement paste, which indicated that the addition of MWCNT was able to increase the vibration-reduction capacity of cement paste. It was found that increasing content of MWCNT led to greater improvement of loss factor of cement paste, which is
TABLE 3: Damping ratio $(\xi)$ of specimens and their improvement $\Delta$ (\%).

\begin{tabular}{|c|c|c|c|}
\hline Samples & $\xi$ & Average & $\Delta(\%)$ \\
\hline \multirow{6}{*}{$\mathrm{CO}$} & 0.0212 & \multirow{6}{*}{$0.0208( \pm 9.13 \%)$} & \multirow{6}{*}{ - } \\
\hline & 0.0207 & & \\
\hline & 0.0189 & & \\
\hline & 0.0220 & & \\
\hline & 0.0194 & & \\
\hline & 0.0226 & & \\
\hline \multirow{6}{*}{$\mathrm{C} 1$} & 0.0216 & \multirow{6}{*}{$0.0215( \pm 3.26 \%)$} & \multirow{6}{*}{3.40} \\
\hline & 0.0210 & & \\
\hline & 0.0217 & & \\
\hline & 0.0220 & & \\
\hline & 0.0208 & & \\
\hline & 0.0219 & & \\
\hline \multirow{6}{*}{$\mathrm{C} 2$} & 0.0231 & \multirow{6}{*}{$0.0230( \pm 1.74 \%)$} & \multirow{6}{*}{10.5} \\
\hline & 0.0229 & & \\
\hline & 0.0227 & & \\
\hline & 0.0234 & & \\
\hline & 0.0229 & & \\
\hline & 0.0228 & & \\
\hline \multirow{6}{*}{$\mathrm{C} 3$} & 0.0246 & \multirow{6}{*}{$0.0246( \pm 5.28 \%)$} & \multirow{6}{*}{18.3} \\
\hline & 0.0247 & & \\
\hline & 0.0237 & & \\
\hline & 0.0259 & & \\
\hline & 0.0249 & & \\
\hline & 0.0240 & & \\
\hline
\end{tabular}

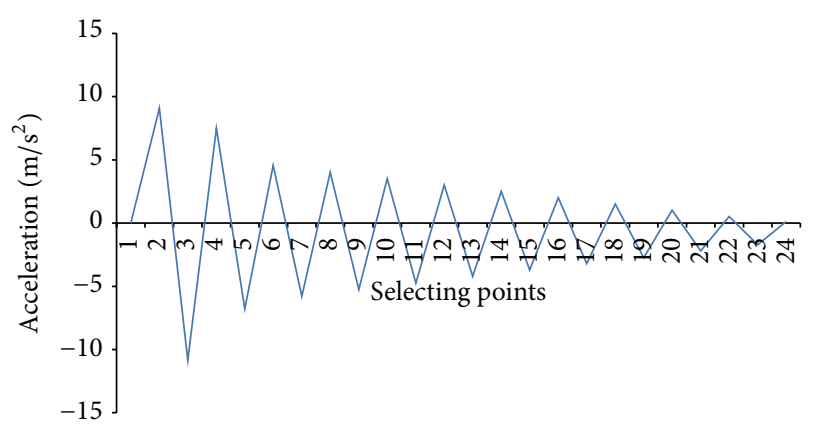

FIGURE 6: Free vibration responses of the specimen.

consistent with the findings of damping ratio in Section 3.2.1. The highest loss factor of the CNT/cement composite was observed in C3 specimen with addition of $0.1 \mathrm{wt} \%$ MWCNT. The 28 days' loss factor of the C3 specimen could reach a $24.30 \%$ higher than that of pure cement paste. In addition, it was also found that the variations of frequency brought little influences to the composite, and the peak value of the loss factor was obtained in $1 \mathrm{~Hz}$ for all the specimens in this study.

3.2.3. Analyses. In the case of cement matrix reinforced with admixtures, the improvement on damping property could be mainly due to two aspects. For one thing, addition of admixtures would inevitably bring some defects to cement matrix, 


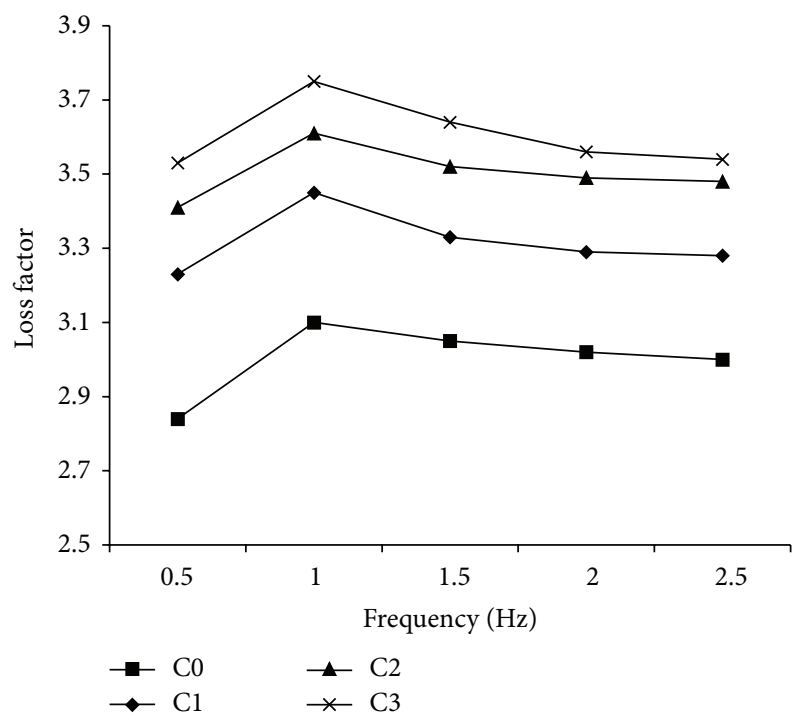

FIGURE 7: Loss factors of cement composite obtained by DMA test.

such as dislocations, phase boundaries, grain boundaries, and various interfaces, and these defects are able to dissipate energy since defects may move slightly and surfaces may slip slightly with respect to one another during vibration [20]; for another, admixtures that are viscoelastic materials could help cement matrix to dissipate energy [20].

It is clearly seen that damping property of cement paste was improved with addition of MWCNT. The reasons for the improvement could be explained as follows:

(1) The multiple intertubes of MWCNT present slippage and internal frictions at the interfaces, which allows energy dissipation by converting mechanical energy into heat. Besides, the nanoholes of MWCNT may produce resonance and alleviate the shock during vibration [15].

(2) The external frictions between MWCNT large interface area and cement matrix contribute to the damping achievement of the cement paste. Well-dispersed MWCNT has great interactive forces with cement matrix and plays a role of bridging effect, as shown in SEM images. During the MWCNT pull-out process, the external frictions could also render energy dissipation through heat release.

(3) The large-area zigzag clinging to cement matrix along MWCNT surface may contribute to the damping achievement to the cement paste [15], which was also shown in SEM images in this study. Besides, the interlocking of MWCNT with hydration products may lead to stress concentration around the reinforced zone, which could facilitate dislocation breakaway from weak pinning points $[21,22]$.

(4) Addition of MWCNT to cement matrix would bring about multiform interfaces and diversified dislocation. The large amounts of interfaces may increase the internal frictions of cement matrix. Besides, the

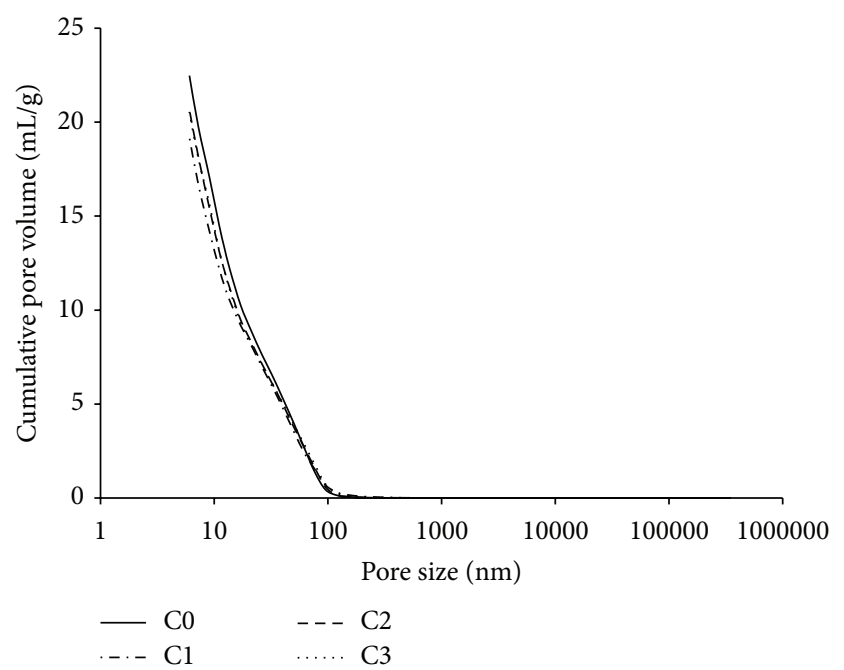

FIGURE 8: Pore size distribution curves of the CNT/cement composite.

diversified dislocation may also delay the formation and promote the viscoelastic retardation under the function of external forces, which would amplify the phase lag when cement composites were subjected to cyclic load.

3.3. Pore Characteristic of the CNT/Cement Composite. Figure 8 and Table 4 present pore characteristic for the pure cement paste and the CNT/cement composite. As seen in Table 4, decreases in porosity and total pore volume were detected in the CNT/cement composite with respect to pure cement paste at the 28th day. These results suggest that MWCNT act as the filler of voids between cement grains. The addition of MWCNT led to a decrease in harmful pores with the diameter larger than $20 \mathrm{~nm}$ by $8.63 \%$, as identified by $\mathrm{Wu}$ and Lian [23]. However, the improvement of MWCNT addition on pore refinement was not as obvious as the results reported by Li et al. [24]. It was supposed that addition of PVP surfactant would inevitably generate some air bubbles during the mixing process and entrapped macropores inside the cement matrix, resulting in the increase of the macropores, and offset the filler effect of MWCNT in this study. Although MWCNT could be well dispersed into cement matrix with the help of PVP surfactant, as shown in SEM images, it is recommended to use deformer to get rid of the air bubbles for a compacted $\mathrm{CNT} /$ cement composite.

3.4. Morphology of the CNT/Cement Composite. SEM micrographs of the hydrated CNT/cement composite structure after 28-day curing are presented in Figure 9. As seen from the figures, the MWCNT was well dispersed in cement matrix by means of surfactant and sonication.

Figure 9(a) shows that an individual MWCNT located at the gap between hydration products and played a significant role of bridging. Figure 9(b) proves that parts of the MWCNT added in the cement matrix were well dispersed and the individual MWCNT was firmly wedged into 


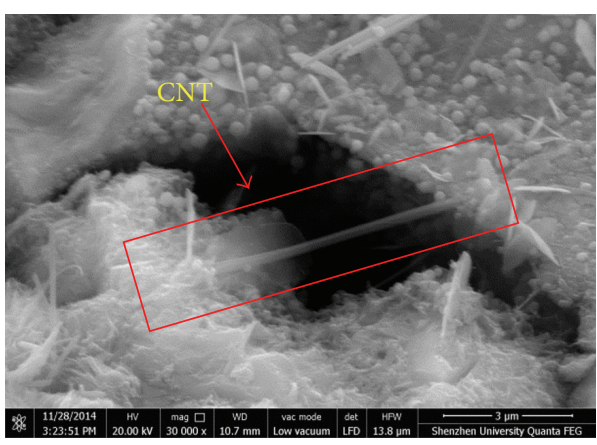

(a) $0.033 \% \mathrm{MWCNT} \times 30 \mathrm{~K}$

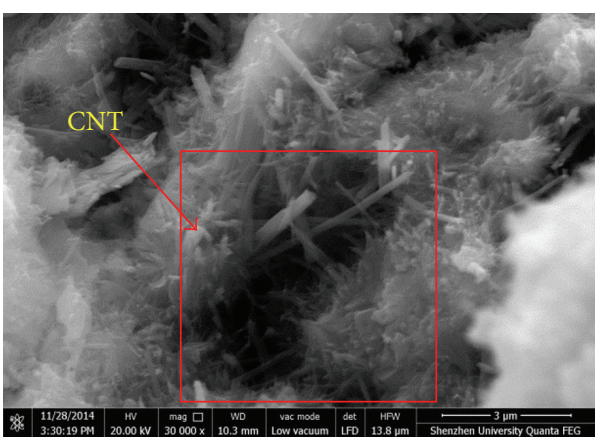

(c) $0.1 \% \mathrm{MWCNT} \times 30 \mathrm{~K}$

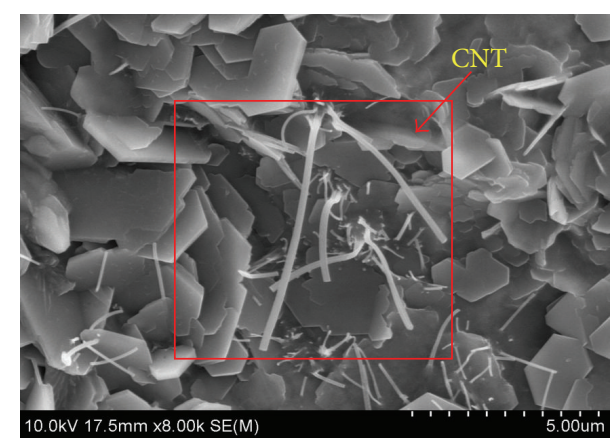

(b) $0.033 \% \mathrm{MWCNT} \times 8 \mathrm{~K}$

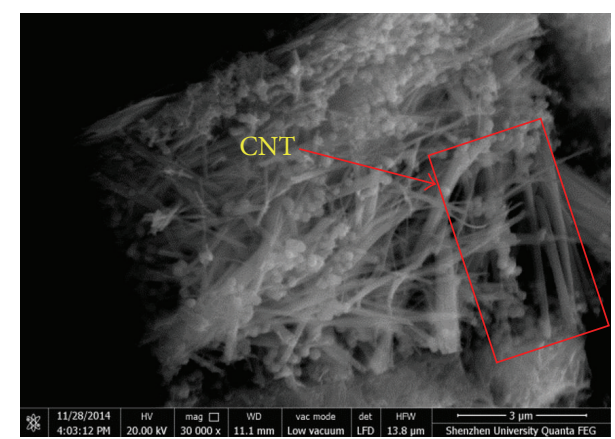

(d) $0.1 \% \mathrm{MWCNT} \times 30 \mathrm{~K}$

FIGURE 9: SEM images of CNT/cement composite after 28-day curing.

TABle 4: Pore characteristic of specimens.

\begin{tabular}{lc}
\hline Specimen & Porosity $(\%)$ \\
\hline C0 & 26.95 \\
C1 & 25.53 \\
C2 & 25.80 \\
C3 & 26.19 \\
\hline
\end{tabular}

the cement hydration products, which would lead to better interconnection between hydration products. In Figure 9(c), MWCNT was found to interlock with hydration products, which would provide higher stress when crack goes straight toward MWCNT reinforced zone area and convert the path of the crack to other places with lower resistance. Figure 9(d) shows that MWCNT presents a zigzag bridging between two neighboring grains boundaries, which may contribute to the damping achievement to the cement composite.

\section{Discussions}

Our results confirm that CNT has a beneficial effect on increasing the damping property of cement matrix. The increased flexural strengths of CNT samples proved its potential application in aspect of damping behavior. The better damping property of the CNT/cement composite is mainly associated with various ways of energy dissipation including internal frictions, external frictions, and multiform interfaces, as proposed by Luo et al. [22]. It should be stressed that good dispersion of CNT in cement matrix is important for the vibration-reduction behavior in this study. The friction regime relies on the bridging effect of CNT during experiment and dissipates the energy in the place where CNT interacts well with cement matrix.

$\mathrm{CNT} /$ cement composite could be a promising and outstanding admixture for high performance concrete so that concrete could maintain high mechanical strength and provide good damping ability. It is highly expected to apply CNT to civil infrastructures to alleviate the dynamic vibration response and damage or fatigue, in order to meet the safe and comfort needs of the people.

It is well known that temperature would play an important role in affecting the damping property of civil infrastructure. Further work on investigating the vibration-reduction behavior of CNT/cement composite in different temperature is warranted in order to meet the comfort and safety of people in different areas.

\section{Conclusions}

This paper presents the results of investigation on damping property of cement paste incorporated with MWCNT. Cement paste samples with four different concentrations of MWCNT (0 wt $\%, 0.033 \mathrm{wt} \%, 0.066 \mathrm{wt} \%$, and $0.1 \mathrm{wt} \%$ ) were designed for this study. Morphology of MWCNT in cement matrix and its effect on the flexural strength, porosity, damping ratio, and loss factor were investigated. The following conclusions were drawn from the study:

(1) The flexural strengths of cement paste samples were improved with addition of MWCNT. At the dosage of 
$0.1 \mathrm{wt} \%$ of MWCNT, the CNT/cement composite has the highest flexural strength in this study.

(2) Samples incorporated with MWCNT have better damping property than the pure cement mortar. It is attributed to internal frictions, external frictions, and multiform interfaces.

(3) With addition of the MWCNT in cement paste, pores with a diameter of bigger than $20 \mathrm{~nm}$ are likely to be refined.

(4) MWCNT was well dispersed in cement paste with the help of surfactant in combination of ultrasonication. The bridging effect and network formation of MWCNT were observed in morphology study.

\section{Conflict of Interests}

The authors declare no conflict of interests.

\section{Acknowledgments}

Financial support of this study by the Shenzhen Strategic Emerging Industry Development Special Fund (Project no. JCYJ20150625102603853), Guangdong Province Science and Technology Plan Projects (Project no. 2015A010105029), and the Ministry of Science and Technology for the 973-Project (Grant no. 2011CB013604) is gratefully acknowledged.

\section{References}

[1] J.-P. Salvetat, J.-M. Bonard, N. H. Thomson et al., "Mechanical properties of carbon nanotubes," Applied Physics A, vol. 69, no. 3, pp. 255-260, 1999.

[2] T. Belytschko, S. P. Xiao, G. C. Schatz, and R. S. Ruoff, "Atomistic simulations of nanotube fracture," Physical Review B, vol. 65, no. 23, Article ID 235430, 2002.

[3] B. K. Kaushik, S. Goel, and G. Rauthan, "Future VLSI interconnects: optical fiber or carbon nanotube-a review," Microelectronics International, vol. 24, no. 2, pp. 53-63, 2007.

[4] J. P. Ou, Structural Vibration Control-Active, Semi-Active and Smart Control, Science Press, Beijing, China, 2003.

[5] S. F. Nabavi, "Influence of polymers on concrete damping properties," in Proceedings of the European Conference of Chemical Engineering, and European Conference of Civil Engineering, and European Conference of Mechanical Engineering, and European Conference on Control, pp. 28-33, World Scientific and Engineering Academy and Society (WSEAS), November 2010.

[6] W. G. Wong, P. Fang, and J. K. Pan, "Dynamic properties impact toughness and abrasiveness of polymer-modified pastes by using nondestructive tests," Cement and Concrete Research, vol. 33, no. 9, pp. 1371-1374, 2003.

[7] S. Wen and D. D. L. Chung, "Enhancing the vibration reduction ability of concrete by using steel reinforcement and steel surface treatments," Cement and Concrete Research, vol. 30, no. 2, pp. 327-330, 2000.

[8] Y. Xu and D. D. L. Chung, "Effect of carbon fibers on the vibration-reduction ability of cement," Cement and Concrete Research, vol. 29, no. 7, pp. 1107-1109, 1999.
[9] S. Xu, J. Liu, and Q. Li, "Mechanical properties and microstructure of multi-walled carbon nanotube-reinforced cement paste," Construction and Building Materials, vol. 76, pp. 16-23, 2015.

[10] J. Ning, J. Zhang, Y. Pan, and J. Guo, "Fabrication and mechanical properties of $\mathrm{SiO}_{2}$ matrix composites reinforced by carbon nanotube," Materials Science and Engineering A, vol. 357, no. 1-2, pp. 392-396, 2003.

[11] K. P. Saffar, A. R. Najafi, M. H. Moeinzadeh, and L. J. Sudak, "A finite element study of crack behavior for carbon nanotube reinforced bone cement," World Journal of Mechanics, vol. 3, no. 5, pp. 13-21, 2013.

[12] R. L. Dai and W. H. Liao, "Modeling of carbon nanotube composites for vibration damping," in Nanosensors, Microsensors, and Biosensors and Systems, vol. 6528 of Proceedings of SPIE, p. 10, International Society for Optics and Photonics, April 2007.

[13] M. Tehrani, M. Safdari, A. Y. Boroujeni et al., "Hybrid carbon fiber/carbon nanotube composites for structural damping applications," Nanotechnology, vol. 24, no. 15, Article ID 155704, 2013.

[14] L. Zheng, X. S. Huo, and Y. Yuan, "Experimental investigation on dynamic properties of rubberized concrete," Construction and Building Materials, vol. 22, no. 5, pp. 939-947, 2008.

[15] Z. Duan and J. Luo, "Effect of multi-walled carbon nanotubes on the vibration-reduction behavior of cement," in International Conference on Smart Materials and Nanotechnology in Engineering, 64230R, vol. 6423 of Proceedings of the SPIE, International Society for Optics and Photonics, July 2007.

[16] T.-L. Wang and C.-G. Tseng, "Polymeric carbon nanocomposites from multiwalled carbon nanotubes functionalized with segmented polyurethane," Journal of Applied Polymer Science, vol. 105, no. 3, pp. 1642-1650, 2007.

[17] X.-L. Xie, Y.-W. Mai, and X.-P. Zhou, "Dispersion and alignment of carbon nanotubes in polymer matrix: a review," Materials Science and Engineering R: Reports, vol. 49, no. 4, pp. 89-112, 2005.

[18] M. S. Konsta-Gdoutos, Z. S. Metaxa, and S. P. Shah, "Multiscale mechanical and fracture characteristics and early-age strain capacity of high performance carbon nanotube/cement nanocomposite," Cement and Concrete Composites, vol. 32, no. 2, pp. 110-115, 2010.

[19] A. Sobolkina, V. Mechtcherine, V. Khavrus et al., "Dispersion of carbon nanotubes and its influence on the mechanical properties of the cement matrix," Cement and Concrete Composites, vol. 34, no. 10, pp. 1104-1113, 2012.

[20] D. D. L. Chung, "Structural composite materials tailored for damping," Journal of Alloys and Compounds, vol. 355, no. 1-2, pp. 216-223, 2003.

[21] M. Hakamada, H. Watanabe, T. Kuromura, Y. Chen, H. Kusuda, and M. Mabuchi, "Effects of pore characteristics finelycontrolled by spacer method on damping capacity of porous aluminum," Materials Transactions, vol. 50, no. 2, pp. 427-429, 2009.

[22] J. Luo, Z. Duan, G. Xian, Q. Li, and T. Zhao, "Damping performances of carbon nanotube reinforced cement composite," Mechanics of Advanced Materials and Structures, vol. 22, no. 3, pp. 224-232, 2015.

[23] Z. W. Wu and H. Z. Lian, "High performance concrete," 396, 1999.

[24] G. Y. Li, P. M. Wang, and X. Zhao, "Mechanical behavior and microstructure of cement composites incorporating surfacetreated multi-walled carbon nanotubes," Carbon, vol. 43, no. 6, pp. 1239-1245, 2005. 

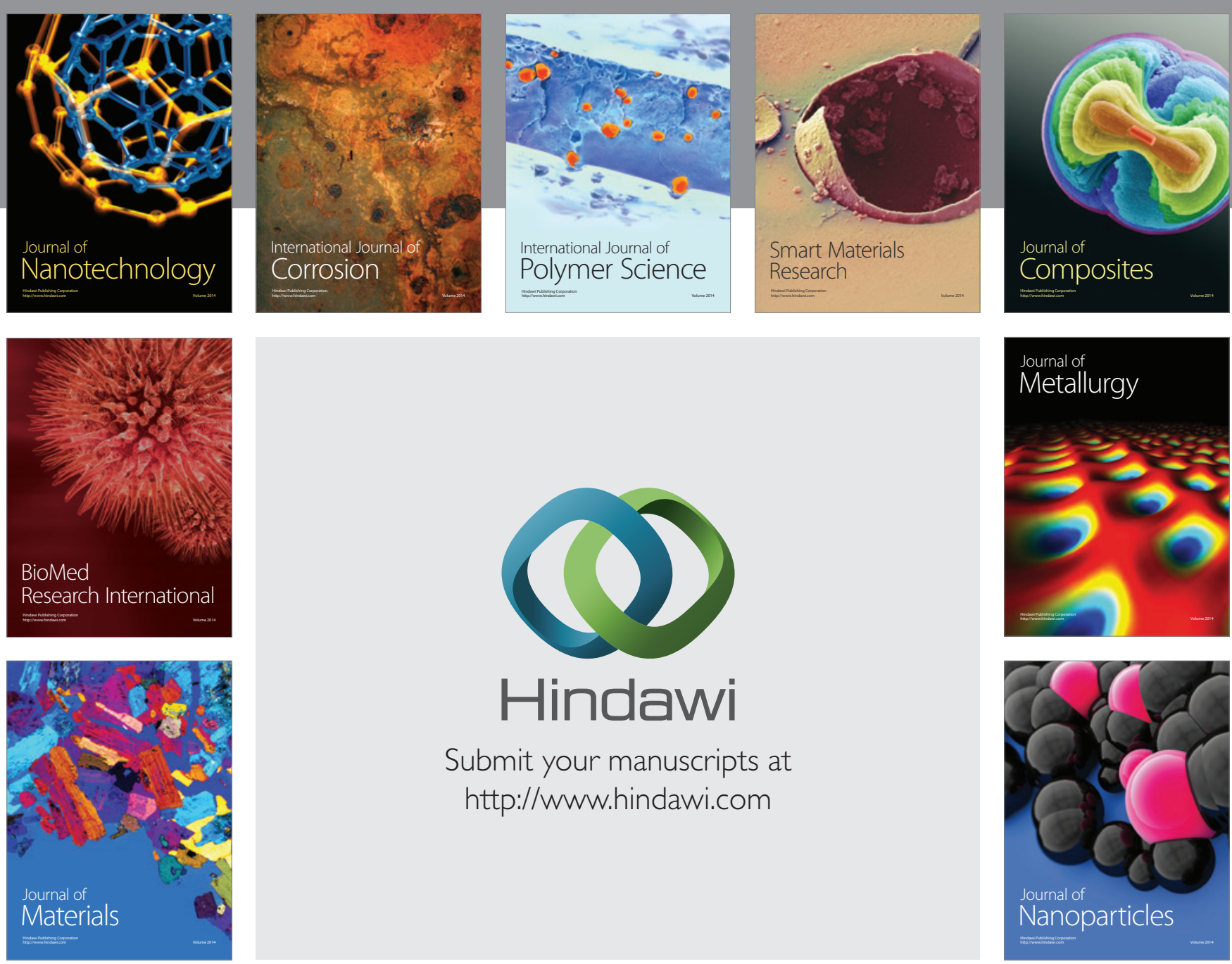

Submit your manuscripts at http://www.hindawi.com
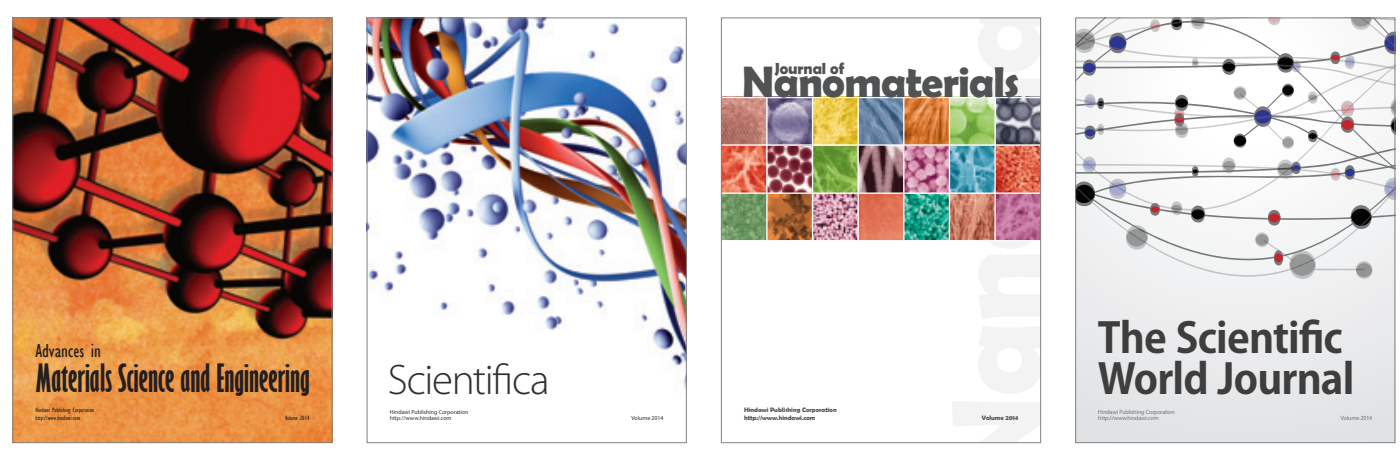

\section{The Scientific World Journal}
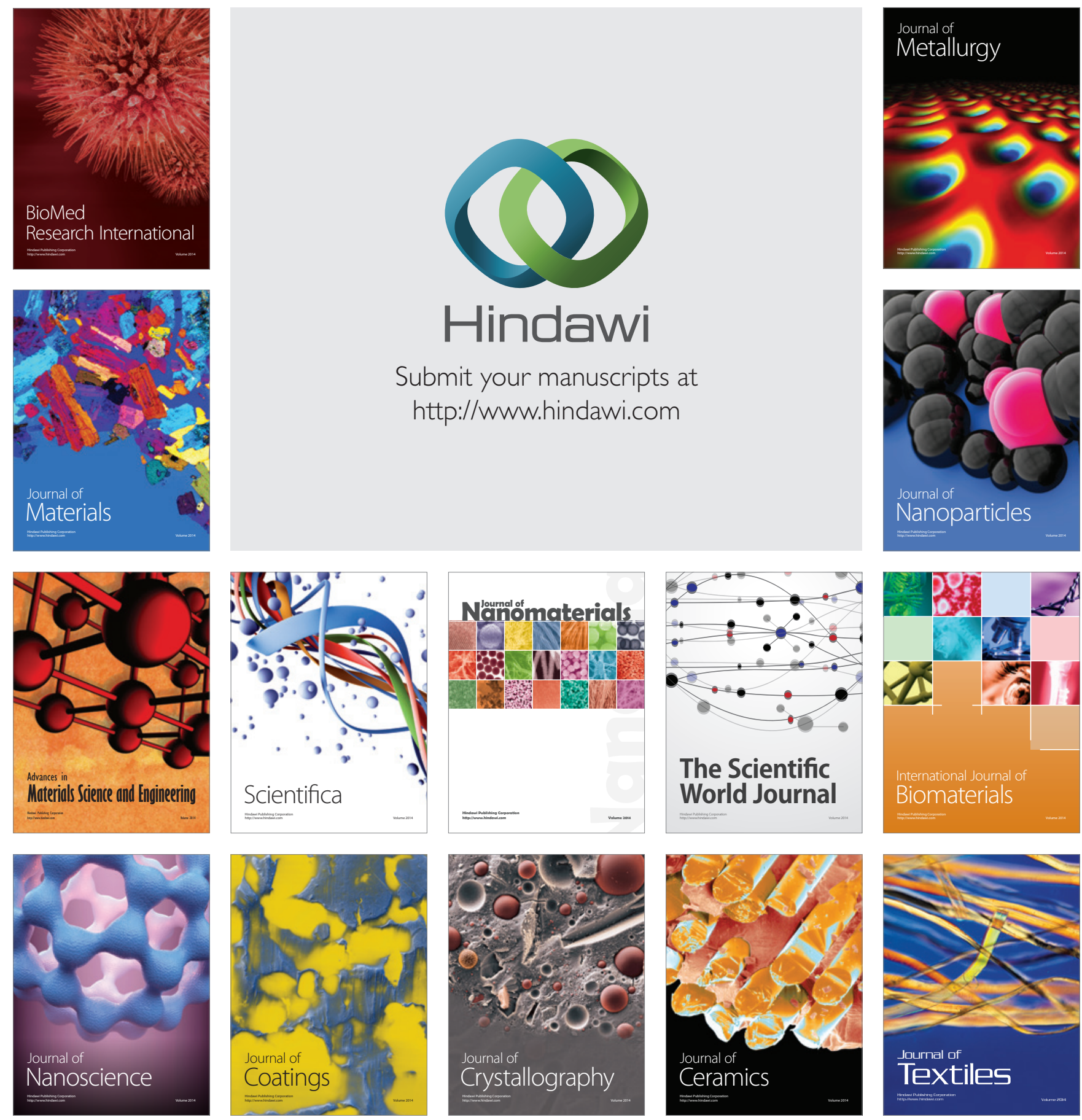